\title{
Response to cimetidine in a 1-year-old child with PFAPA syndrome
}

\author{
Kazuto Taniguchi ${ }^{1}$, Nobuyasu Ono ${ }^{2}$, Tatsuya Sakai ${ }^{1}$, Yasunobu Ichiyama ${ }^{1}$, Kazuyasu \\ Uemichi $^{1}$ \\ ${ }^{1}$ Cho-ritsu Tara Hospital, Tara, Saga, ${ }^{2}$ Department of Paediatrics, Ureshino Medical Center, Ureshino, Saga, Japan. E-mail: \\ tgene1@po.hagakure.ne.jp \\ Received: 10th May 2016, Received: 12th July 2016, Accepted: 29th August 2016
}

\begin{abstract}
SUMMARY: Taniguchi K, Ono N, Sakai T, Ichiyama Y, Uemichi K. Response to cimetidine in a 1-year-old child with PFAPA syndrome. Turk J Pediatr 2016; 58: 687-689.

Periodic fever, aphthous stomatitis, pharyngitis, and cervical adenitis (PFAPA) syndrome is characterized by periodic febrile attacks recurring regularly every 2 to 8 weeks. Although tonsillectomy is offered as an effective treatment, the effectiveness of cimetidine treatment is still controversial. In this article, we describe two cases. A 1-year-old girl with PFAPA syndrome received cimetidine treatment and febrile attacks were reduced. Tonsillectomy was successfully performed on a 6-year-old boy with PFAPA syndrome. We suggest that the use of cimetidine may reduce febrile attacks of PFAPA syndrome until an age that is safer for tonsillectomy.
\end{abstract}

Key words: cimetidine, tonsillectomy, PFAPA syndrome, febrile attacks.

Periodic fever, aphthous stomatitis, pharyngitis, and cervical adenitis (PFAPA) syndrome is characterized by periodic high fever lasting 3 to 6 days and recurring regularly every 2 to 8 weeks. The fever is also associated with aphthous stomatitis, pharyngitis, and cervical adenitis $^{1-4}$. Although tonsillectomy is offered as an effective treatment ${ }^{5-9}$, the effectiveness of cimetidine treatment is still controversial $3,4,10-12$. We report here the effectiveness of cimetidine treatment, which has reduced febrile attacks of PFAPA syndrome.

\section{Case Reports}

Case 1

A 1-year-old girl with an unremarkable medical history suffered from periodic febrile attacks accompanied by aphthous stomatitis and pharyngitis every 4 to 8 weeks. She was diagnosed with PFAPA syndrome after 1 year from the first febrile attack in accordance with the diagnostic criteria advocated by Thomas et $\mathrm{al}^{3}$. Blood tests showed that leukocytes ranged from 10.930 to $18.800 / \mathrm{mm}^{3}$ without neutropenia. This suggested that febrile attacks were not due to cyclic neutropenia, a major differential diagnosis. In febrile attacks, prednisolone $(0.5 \mathrm{mg} / \mathrm{kg}$, a single dose) was effective in reducing the fever. She was started on cimetidine treatment $(20 \mathrm{mg} / \mathrm{kg}$, twice daily). She has not suffered from a febrile attack for more than 8 months. No side effect was detected due to cimetidine treatment.

\section{Case 2}

A 6-year-old boy with an unremarkable medical history suffered from periodic febrile attacks accompanied by aphthous stomatitis, pharyngitis, and cough every 2 to 8 weeks (Table I). He was diagnosed with PFAPA syndrome in accordance with the same criteria described above at the age of 3 years, although onset was at the age of 1 year. Blood tests showed that leukocytes ranged from 11.130 to $19.730 / \mathrm{mm}^{3}$ without neutropenia. In febrile attacks, prednisolone $(0.5 \mathrm{mg} / \mathrm{kg}$, a single dose or $1 \mathrm{mg} / \mathrm{kg}$, twice a day) was effective in reducing the fever. He underwent tonsillectomy at the age of 6 years to avoid frequent absences from school. He has not suffered from a febrile attack for more than 7 months since having tonsillectomy.

\section{Discussion}

We observed two important clinical issues 
Table I. Characteristics of Two Patients with PFAPA Syndrome.

\begin{tabular}{|c|c|c|c|c|c|}
\hline Case & Sex & $\begin{array}{c}\text { Interval of } \\
\text { febrile attacks }\end{array}$ & Symptoms & $\begin{array}{l}\text { Leukocytes } \\
\text { count }\left(/ \mathrm{mm}^{3}\right)\end{array}$ & Treatment \\
\hline 1 & $\mathrm{~F}$ & $4-8$ weeks & $\begin{array}{c}\text { High fever, } \\
\text { pharyngitis, } \\
\text { aphthous stomatitis }\end{array}$ & $\begin{array}{c}10,930- \\
18,800\end{array}$ & Cimetidine \\
\hline 2 & M & 2-8 weeks & $\begin{array}{l}\text { High fever, cough } \\
\text { pharyngitis, } \\
\text { aphthous stomatitis, }\end{array}$ & $\begin{array}{c}11,130- \\
19,730\end{array}$ & $\begin{array}{c}\text { PSL } \\
\text { Tonsillectomy }\end{array}$ \\
\hline
\end{tabular}

F: female, M: male, PSL: prednisolone

from our cases. Cimetidine treatment reduced febrile attacks of PFAPA syndrome. Additionally, tonsillectomy was effective against PFAPA syndrome, as we expected.

Vanoni et al. referred to more than $80 \%$ effectiveness of orally given prednisolone or betamethasone as treatment for febrile attacks ${ }^{13}$. Although they also referred to possibility of colchicine, cimetidine and anakinra as prophylactic treatment, the effectiveness of these drugs is still controversial ${ }^{13}$.

Cimetidine treatment can reduce febrile attacks of PFAPA syndrome. Cimetidine is a common $\mathrm{H} 2$ antagonist that inhibits suppressor CD8+ T-lymphocyte activation and chemotaxis ${ }^{11,12}$. Thomas et al. ${ }^{3}$, Feder et al. ${ }^{4}$, and Wurster et al. ${ }^{12}$ reported $43 \%, 27 \%$, and $24 \%$ effectiveness, respectively, of cimetidine for PFAPA syndrome. Because the effectiveness described above are not sufficiently high, some pediatricians hesitate to prescribe cimetidine for PFAPA syndrome. Our patient showed a reduction of febrile attacks of PFAPA syndrome.

Tonsillectomy is effective against PFAPA syndrome. Previous reports have shown 63$100 \%$ effectiveness of tonsillectomy for PFAPA syndrome $3,4,6-8,12$. Our case 2 also showed effectiveness of tonsillectomy for PFAPA syndrome.

Febrile attacks of PFAPA syndrome can begin, at the earliest, at the age of 1 month ${ }^{1,3,8,14}$. Complications following tonsillectomy are more common in children younger than 3 years ${ }^{15}$. Although prednisolone treatment is highly effective for the treatment of febrile attacks of PFAPA syndrome, it shortens the interval of febrile attacks ${ }^{12,16}$. Cimetidine treatment may be useful for reducing febrile attacks of PFAPA syndrome until the age of 3 years.
In conclusion, cimetidine treatment can reduce febrile attacks and tonsillectomy is effective against PFAPA syndrome in our cases. We propose to use cimetidine to reduce febrile attacks of PFAPA syndrome until the age of 3 years. Cimetidine treatment could be recommended to reduce the attacks of PFAPA syndrome. Further studies are needed to determine whether cimetidine treatment can become a main therapeutic strategy prior to tonsillectomy.

\section{Acknowledgements}

The authors would like to thank Motosuke Katsura, Kotaro Ishimaru, Shigetoshi Sumita, Shunroku Koga, and Shinobu Taniguchi for technical assistance and helpful discussions.

\section{REFERENCES}

1. Marshall GS, Edwards KM, Butler J, Lawton AR. Syndrome of periodic fever, pharyngitis, and aphthous stomatitis. J Pediatr 1987; 110: 43-46.

2. Marshall GS, Edwards KM, Lawton AR. PFAPA syndrome. Pediatr Infect Dis J 1989; 8: 658-659.

3. Thomas KT, Feder HM Jr, Lawton AR, Edwards KM. Periodic fever syndrome in children. J Pediatr 1999; 135: 15-21

4. Feder HM, Salazar JC. A clinical review of 105 patients with PFAPA (a periodic fever syndrome). Acta Paediatr 2010; 99: 178-184.

5. Galanakis E, Papadakis CE, Giannoussi E, Karatzanis AD, Bitsori M, Helidonis ES. PFAPA syndrome in children evaluated for tonsillectomy. Arch Dis Child 2002; 86: 434-435.

6. Renko M, Salo E, Putto-Laurila A, et al. A randomized, controlled trial of tonsillectomy in periodic fever, aphthous stomatitis, pharyngitis, and adenitis syndrome. J Pediatr 2007; 151: 289-292.

7. Licameli G, Jeffrey J, Luz J, Jones D, Kenna M. Effect of adenotonsillectomy in PFAPA syndrome. Arch Otolaryngol Head Neck Surg 2008; 134: 136-140.

8. Garavello W, Romagnoli M, Gaini RM. Effectiveness of adenotonsillectomy in PFAPA syndrome: a randomized study. J Pediatr 2009; 155: 250-253. 
9. Peridis S, Pilgrim G, Koudoumnakis E, Athanasopoulos I, Houlakis M, Parpounas K. PFAPA syndrome in children: A meta-analysis on surgical versus medical treatment. Int J Pediatr Otorhinolaryngol 2010; 74: 1203-1208.

10. Feder HM Jr. Cimetidine treatment for periodic fever associated with aphthous stomatitis, pharyngitis, and cervical adenitis. Pediatr Infect Dis J 1992; 11: 318321.

11. Pinto A, Lindemeyer RG, Sollecito TP. The PFAPA syndrome in oral medicine: differential diagnosis and treatment. Oral Surg Oral Med Oral Pathol Oral Radiol Endod 2006; 102: 35-39.

12. Wurster VM, Carlucci JG, Feder HM Jr, Edwards KM. Long-term follow-up of children with periodic fever, aphthous stomatitis, pharyngitis, and cervical adenitis syndrome. J Pediatr 2011; 159: 958-964.
13. Vanoni F, Theodoropoulou K, Hofer M. PFAPA syndrome: a review on treatment and outcome. Pediatr Rheumatol Online J 2016; 14: 38.

14. Tasher D, Somekh E, Dalal I. PFAPA syndrome: new clinical aspects disclosed. Arch Dis Child 2006; 91: 981-984.

15. Baugh RF, Archer SM, Mitchell RB, et al. Clinical practice guideline: tonsillectomy in children. Otolaryngol Head Neck Surg 2011; 144: S1-30.

16. Murata T, Okamoto N, Shimizu T, Tamai H. Diagnosis and management of periodic fever with aphthous pharyngitis and adenitis (PFAPA). Jpn J Clin Immunol 2007; 30: 101-107. 